\title{
DOCUMENTING THE LIGHT SENSITIVITY OF SPANISH LEVANTINE ROCK ART PAINTINGS
}

\author{
J. M. del Hoyo-Meléndez ${ }^{\text {a }}$ J. L. Lerma ${ }^{\text {b }}$ E. López-Montalvo ${ }^{c}$, V. Villaverde ${ }^{\text {d }}$ \\ ${ }^{a}$ Laboratory of Analysis and Non-Destructive Investigation of Heritage Objects, The National Museum in Krakow, \\ ul. Piłsudskiego 14, 31-109 Krakow, Poland - jdelhoyo@ muzeum.krakow.pl \\ ${ }^{\mathrm{b}}$ Department of Cartographic Engineering, Geodesy and Photogrammetry, Universitat Politècnica de Valencia, Camino de Vera \\ s/n, Edificio 7i, 46022 Valencia, Spain - jllerma@cgf.upv.es \\ ${ }^{c}$ French National Centre for Scientific Research, TRACES UMR 5608 - Université de Toulouse II - Jean Jaurès. 5, Allée \\ Antonio Machado, 31058 Toulouse, France - esthermontalv@gmail.com \\ ${ }^{\mathrm{d}}$ Departament of Prehistory and Archaeology, Universitat de València, Blasco Ibañez, 28, 46010 Valencia, Spain - \\ Valentin.Villaverde@uv.es
}

KEY WORDS: Exposure, Light, Microfading spectrometry, Photosensitivity, Pigments, Spanish Levantine Rock art

\begin{abstract}
:
A case study to evaluate the use of microfading spectrometry (MFS) for the study of colored systems found in prehistoric rock art paintings was conducted in the Cova Remígia rock-shelter, Castellón (Spain). This rock shelter is part of the rock art sites of the Mediterranean basin on the Iberian Peninsula included in UNESCO's World Heritage List. Some of the paintings belonging to this group are exposed to environmental factors including natural daylight, wind and rain, depending on the time of the day and the season of the year. Therefore, their preservation is a major concern to stakeholders and researchers responsible for protecting and studying these prehistoric paintings. The experimental work in Cova Remigia focused on measuring the reflectance curves (400-700 $\mathrm{nm}$ ) and determining the photostability of various areas containing red and black pigments on the rock art paintings. The preliminary results indicate that MFS is a suitable technique for studying the response to light of rock/pigment systems found in rock art sites. The advantages and limitations of the technique are discussed.
\end{abstract}

\section{INTRODUCTION}

The preservation of prehistoric rock art paintings is a priority to cultural heritage professionals around the world since some of these sites are exposed to environmental elements, which can accelerate their degradation increasing the risk of losing such a valuable piece of information of past societies. Climate changes are having and will continue to have an impact on the rates of degradation of cultural heritage sites including open-air shelters containing rock art (Brimblecombe et al., 2011). It is known that warming temperatures, higher seasonal variable precipitation, and increased wind speeds have adverse effects on these open-air shelters. Local factors are also responsible for accelerating the deterioration and may include moisture conditions and composition and properties of soils (Giesen et al., 2014). It has been observed that these important sites are at stake due to the action of the aforementioned factors in combination with direct solar irradiation. Therefore, it is hoped that this research will contribute to the development of a reliable protection plan that takes into account the potential damaging effect of sunlight acting in conjunction with other expected local and global environmental threats.

Cova Remígia paintings can be selected as a good example since they are located in a complex opened-air rock site that is full of shelters and contains a large variety of depictions. Cova Remígia is part of the Spanish Levantine rock art paintings of the Mediterranean basin on the Iberian Peninsula declared World Heritage by UNESCO in 1998. The uniqueness of these paintings in the European prehistoric framework as well as the accelerated degradation of the site due to its geographical location justifies the selection of Cova Remígia as an ideal case study.
Although the preservation of rock art paintings is an important research topic, there is a present need for developing and testing new methods that can be used for assessing the current state of the materials and their potential long-term behaviour as a result of exposure to environmental elements. It is generally believed that rock art pigments (i.e. haematite, limonite, clay minerals, and charcoal) are not very light sensitive. However, some authors have demonstrated that exposure to sunlight can have adverse effects on these systems due to thermal and photochemical degradation of the historic materials (DíezHerrero et al., 2009). It has been determined that thermal deterioration is mostly observed in the host rock and is caused by the non-uniform distribution of temperature at the core of the material. Heating from insolation results in rapid temperature variations on the rock surface relative to its interior causing different types of physical failure, including fissuring, peeling, flaking, and crumbling. On the other hand, photochemical degradation is typically experienced by the chromophores present in the paint layer. This is a surface effect and the degree of color change depends on the chemical composition of the pigment. Moreover, the presence of light degradable minerals can also produce undesirable changes in appearance when the historic paints become in contact with oxygen and water.

A traditional accelerated aging study on surrogate samples with similar properties to those of rock art paintings conducted by David (2008) revealed that binders can influence the overall photostability of a paint system. Several factors such as the physico-chemical properties of the paint system and its later interaction with the rock support can result in catalytic, negligible, or protective effects on the pigments. The binders used in the aforementioned study included six vegetable 
substances, namely Jatobá resin, Copaiba balsam, Pequi oil, Babassu oil, pine resin, and gum arabic. In addition, four animal-based substances were tested, namely blood, urine, pork lard and egg. The substrate used was a limestone of the calcarenite type from Alicante Spain called Bateig Azul. This is a porous material with fine granulometry. The study included accelerated photoaging tests conducted on these surrogate samples, but no tests were carried out on actual rock art panels. For all these reasons, a study that focuses on evaluating and documenting the photostability of rock art colored systems on site was performed by undertaking in situ lightfastness measurements.

The surface characteristics (i.e. color and photostability) of rock/pigment systems found in this Spanish Levantine rock art site were studied in situ by reflectance spectroscopy coupled with accelerated aging. The technique proposed for this investigation is called microfading spectrometry (MFS), which is a method for assessing the susceptibility of cultural heritage objects to light-fading using a high power light source in combination with an optical setup and a VIS-spectrometer. This method allows real time monitoring of spectral changes of a small area $(\sim 0.5 \mathrm{~mm})$ of a cultural heritage object by exposing it to light. This method was developed by Whitmore and coworkers (1999) and has been extensively used to study the lightfastness of cultural objects (Ford, 2009, del HoyoMeléndez and Mecklenburg, 2010, Tse et al., 2010). A similar microfading study using samples from the Mogao Grottoes in China was previously conducted by Druzik (2010). However, the objective of our study was to evaluate the performance of the technique on site. The results can be considered complementary to other chemical characterization studies of pigments previously conducted on related sites (Roldán et al., 2010) as well as to earlier integral documentation work using 2D and 3D digital techniques (Domingo et al., 2013).

This research specifically deals with the testing of spectral techniques in the visible range field paying particular attention to new developments in optical techniques that have an impact on the instruments used to monitor the spectrum of cultural heritage surfaces. In this sense, MFS is a fairly new technique that provides not only information about the current state of the material, but also gives information about the potential changes that the material may experience as a result of uncontrolled and long light exposure. The accelerated light aging component of the technique provides an ideal tool for identifying and implementing case studies that have the goal of studying surface characteristics and their interaction with optical radiation.

The application of microfade testing for evaluating the photostability of rock art paintings was evaluated recognizing its potential as a complementary tool for cultural heritage documentation and chemical characterization. This research constitutes a feasibility study on the use of this technique for the study of rock art and it contributes to the development of experimental guidelines as well as to the identification of possible sources of error at the time of conducting microfading monitoring tests in the field.

\section{MATERIALS AND METHODS}

\subsection{Rock art paintings}

Cova Remígia is one of the most standing sites of ValltortaGassulla region due to the number of motifs, their stylistic variety and the thematic content of the scenes. Discovered in 1934, the research work -graphic recording and analysisdeveloped recently in this site has considerably increased the number of documented figures so far. On one hand, the use of digital enhancement software has allowed us to identify a great quantity of unpublished black figures. On the other hand, energy dispersive X-ray fluorescence (EDXRF) and Raman analysis of these black figures has revealed the use of a black pigment of vegetable origin, an unknown practice in this area so far, and very rare in the rest of the Spanish Levantine rock art territory. The identification of this pigment opens the prospect to obtain a first absolute dating of these paintings whose cultural and chronological framework remains imprecise (López-Montalvo et al., 2014).

The most adequate shelter, scenes, and rock/pigment systems were selected taking into account variables including color and pigment composition derived from previous chemical analysis (López-Montalvo et al., 2014); position and accessibility of the figures considering the limitation of the instrument; exposure of the depictions to light and other environmental factors. A total of six points were determined: 3 in red areas containing $\mathrm{Fe}$ based pigments and another 3 in dark areas containing a black pigment of vegetable origin, most likely coming from charred wood. The criterion used to select spots for analysis was to give preference to areas containing relatively higher brightness and color saturation after visual assessments carried out by a team of archaeologists and scientists. This evaluation revealed that some of the red areas have lower chroma (pigment saturation) most likely due to degradation caused by the environmental factors previously described. In addition, zones containing salt efflorescences were avoided in order to concentrate on the lightfastness of pigments showing no visible interferences. These areas containing well-preserved figures are generally found in the upper sections of the shelters since they are better protected from environmental elements. In any case, the selected figures are representative of the total number of depictions documented until now in Cova Remígia.

In addition, the most favourable testing conditions were selected taking into consideration that part of the paintings are illuminated by direct sunlight during various hours of the day and that there are uneven material properties. These include the use of a light source for accelerated aging having a similar spectral power distribution to that of natural daylight and modifying the original instrumental setup in order to include $\mathrm{UV}$ radiation. It is known that UV contains more damaging wavelengths than visible light and the fading rates of materials can increase when this type of radiation is included in the measurement. Moreover, finding areas of both low specular reflection and absence of salt efflorescence was followed in order to obtain reliable data from the pigmented zones. Experience from previous documentation campaigns has revealed that the total amount of direct sunlight received by the paintings may vary from two to three hours daily depending on the time of the year. These are morning hours that can fluctuate between $7: 30$ and 10:30.

Previous research carried out in other relevant Spanish Levantine rock art sites (Roldán et al., 2010) has revealed that the evaluated zones typically consist of a calcareous rock substrate, painted layers containing both organic and inorganic pigments, and a salt efflorescence layer made primarily of calcium salts such as $\mathrm{CaSO}_{4}$ and $\mathrm{CaCO}_{3}$. These salts form when humidity comes in contact with the rock support, while later salt migration to the surface is a typically occurrence. The 
precipitation of salts has an adverse effect on the internal integrity of the rock support since it is known that mechanical processes such as expansion and contraction take place due to drastic changes in temperature experienced by the host rock. The areas evaluated were those containing red and black pigments. This information allowed us to select the optimal testing parameters and modifying the current instrumental setup since the properties of the materials under evaluation were the main factors affecting the reliability and the reproducibility of the results. A map showing the approximate geographical location of relevant Spanish Levantine rock art sites along with a general view of shelter number $\mathrm{V}$ in Cova Remigia are shown in Figure 1.
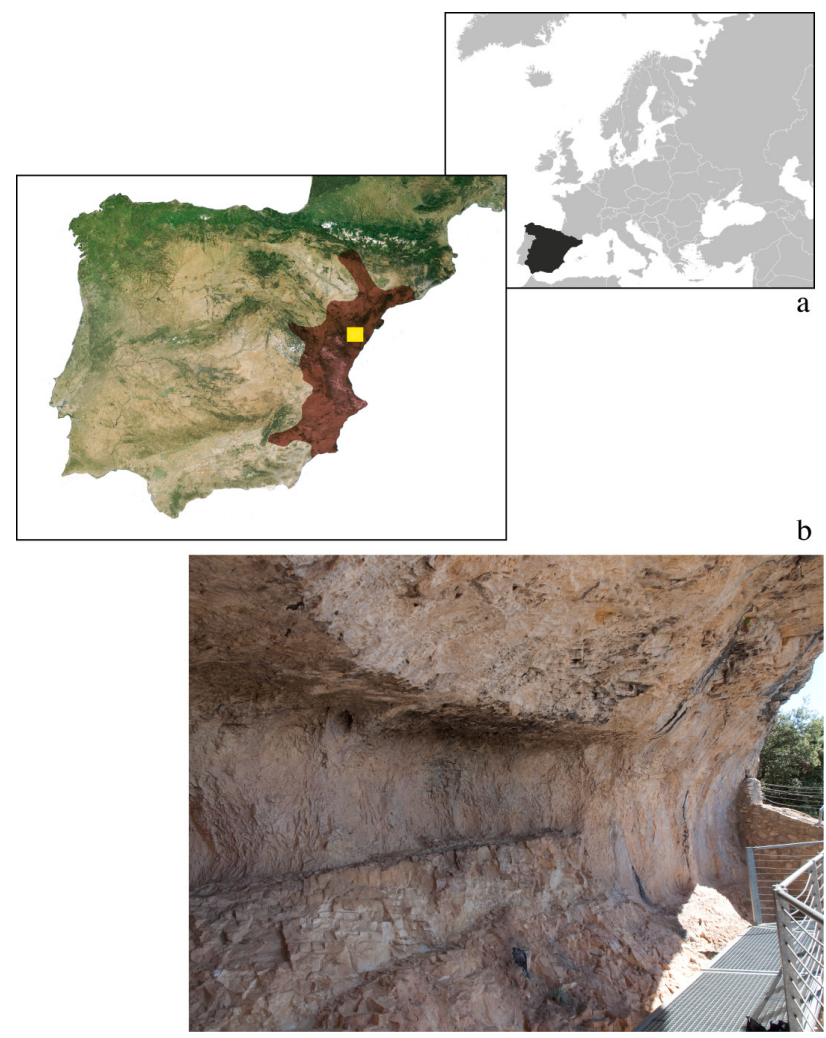

Figure 1. a) Map showing the approximate location of the site in Europe (yellow dot). Maroon color indicates the area covered by Spanish Levantine rock art; b) general view of shelter number $\mathrm{V}$ at Cova Remígia

Figure 2 shows a general view of the zone where the paintings are located from a nearby observation point. More detailed information about the geographical location of Cova Remígia can be found in (Porcar, Breuil \& Obermaier, 1935; Sarriá Boscowich, 1989).

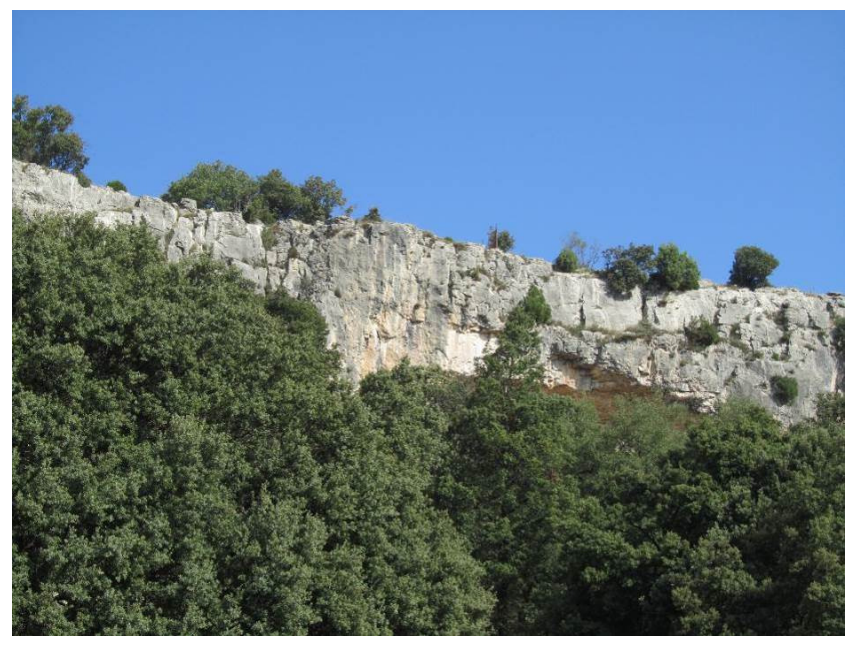

Figure 2. View of the hill (partly covered by trees) where the rock shelter with the paintings is located

\subsection{Microfading spectrometer}

The microfading device used in this study was designed and developed by researchers at the National Museum in Krakow and at the Faculty of Chemistry of the Jagiellonian University (Łojewski et al., 2011) and it is based on the original prototype designed by Whitmore et al. (1999). This instrument consists of a high-power light source, a $0^{\circ} / 45^{\circ}$ geometry optical setup (Fig. 3 ) and a VIS reflectance spectrometer. The high power light source employed is a HPLS 30-04 solid state plasma light source (LIFI) from Thorlabs (New Jersey, USA). The system uses fiber optics to provide non-contact measurement and detection. The size of the illuminated spot is about $0.5 \mathrm{~mm}$, while the estimated intensity measured at the spot is $7.0 \mathrm{Mlx}$. The spectrometer used is an Ocean Optics (Florida, USA) Jaz miniature device. The first visible reflectance spectrum was used as reference and subsequent spectra were collected every $60 \mathrm{~s}$ for a total testing time of $600 \mathrm{~s}$. The integration time was 100 milliseconds and 10 spectra were averaged. Whitmore and co-workers (1999) have observed that instrumental drift is accountable for $\Delta E^{*}$ values, which are less than 0.2 per hour. This is considered acceptable for reasonable sensitive determinations of color changes from fading. The MFS setup is presented in Figure 4.

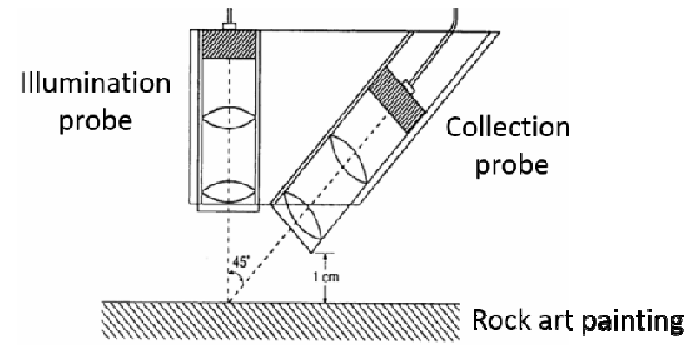

Figure 3. Measurement geometry used for microfade testing. The illumination probe is used to irradiate the material at a 0 degree angle, while the reflected light is collected by the observation probe using a 45 degree orientation relative to the sample (Diagram adapted from Whitmore et al., 1999) 


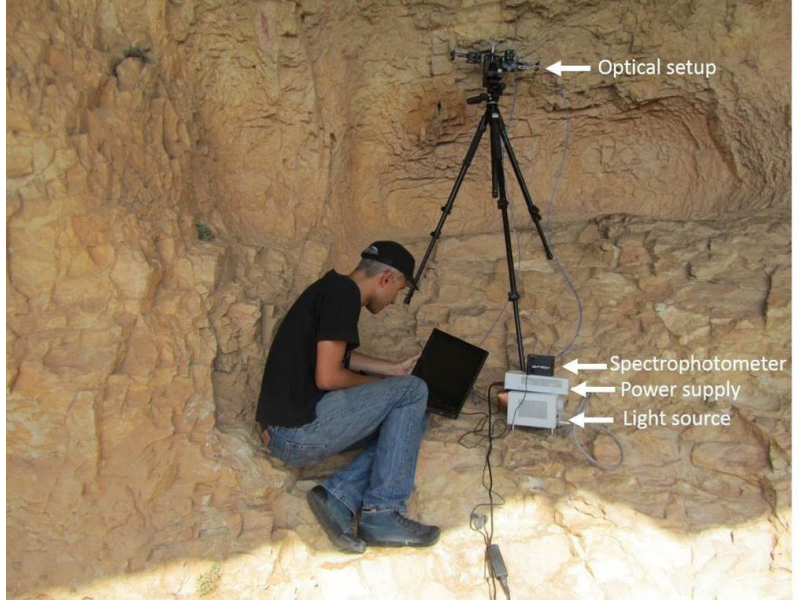

Figure 4. MFS setup used to evaluate the light stability of pigments in Cova Remígia

\subsection{Evaluation of data}

The Commission Internationale de l'Eclairage (CIE) illuminant and standard colorimetric observer combination used was $\mathrm{D}_{65}$ and 2 degree, respectively. Standard illuminants are used in colorimetry to calculate the tristimulus values of reflected colors under specified conditions of illumination. $\mathrm{D}_{65}$ is a standard illuminant intended to represent average daylight illumination conditions with a correlated color temperature of about $6500 \mathrm{~K}$. In addition to standard illuminants, the CIE conducted experiments to quantify the standard observer since the knowledge about the exact distribution of human rods and cone photoreceptors is limited. In addition, the tristimulus values depend on the observer's field of view, while there are large variations between eyes. With the goal of reducing these variables, the CIE developed a color-mapping function called the standard colorimetric observer. This function represents an average human's chromatic response within a $2^{\circ}$ arc inside the fovea since previous research identified this angle as the one containing the largest concentration of color-sensitive cones.

Spectrocolorimetric changes were evaluated using the CIELAB 1976 color space. This is the most traditional color space still employed in many fields including heritage science. The values in the CIE, 1976 color space are $\mathrm{L}^{*}, \mathrm{a}^{*}$, and $\mathrm{b}^{*}$ used to designate lightness-darkness, redness-greenness, and yellowness-blueness, respectively. CIE $\mathrm{L}^{*} \mathrm{a} \mathrm{b}^{*}$ values are calculated from measured tristimulus $\mathrm{X} \mathrm{Y} \mathrm{Z}$ values and the corresponding $\mathrm{Xn}$ Yn $\mathrm{Zn}$ values of the standard illuminant and observer combination used. Reflectance spectra of each test spot were collected and color differences were calculated using the initial spectrum as the basis for comparison. The difference between two spectral measurements recorded at times $t_{1}$ and $t_{2}$ $\left(t_{2}>t_{1}\right)$ is given by:

$$
\Delta \mathrm{E}^{*}=\left[\left(\mathrm{L}_{2}-\mathrm{L}_{1}\right)^{2}+\left(\mathrm{a}_{2}-\mathrm{a}_{1}\right)^{2}+\left(\mathrm{b}_{2}-\mathrm{b}_{1}\right)^{2}\right]^{1 / 2}
$$

where $\Delta \mathrm{E}^{*}$ is the change in color based on the three parameters explained above.

The reaction rates of the surveyed areas were compared to those observed for Blue Wool (BW) standards 1-3 under the same experimental conditions since they are still considered the only reasonable reference materials for evaluating the lightfastness of unknown colorants (Bacci et al., 2004). The BW material is ISO standardized for the evaluation of photostability with BW 8 being the most and BW 1 the least stable. A typical light sensitivity scale used in MFS is BW 1: extremely high, BW 2 very high, and BW 3: high. Materials showing higher stability than BW 3 are considered relatively stable to light when evaluated with MFS, while those showing much higher permanence remain out of the sensitivity range of this technique.

\section{RESULTS}

The light-stability assessment conducted in Cova Remígia focused on the study of rock/pigment systems containing red and black colorants. Two photographs showing the approximate location of a red and a black painted zone are shown in Figure 5. The irregularities of the rock support can be observed. Sometimes the painted area can have a very irregular support increasing the difficulty at the time of setting up the measurement. The unevenness of the surfaces and the poor access to the testing points made the task of setting up the measurement very difficult. Getting access to the painted areas was not always ideal due to the lack of surfaces available to place the stand supporting the measuring probes in order to obtain a reliable measurement. Therefore, a considerable amount of time was spent on just setting up the measurement, while the measurement itself took only 10-15 minutes. The rock substrate may also present a glossy layer that can introduce a specular reflection component producing unstable subsequent spectra if recorded in real time. Hence, it is important to emphasize that the MFS instrument is very sensitive to movement and glossy surface effects. This was evidenced by the extremely large fluctuations in Delta $\mathrm{E}^{*}$ values (not shown) sometimes registered during measurements.
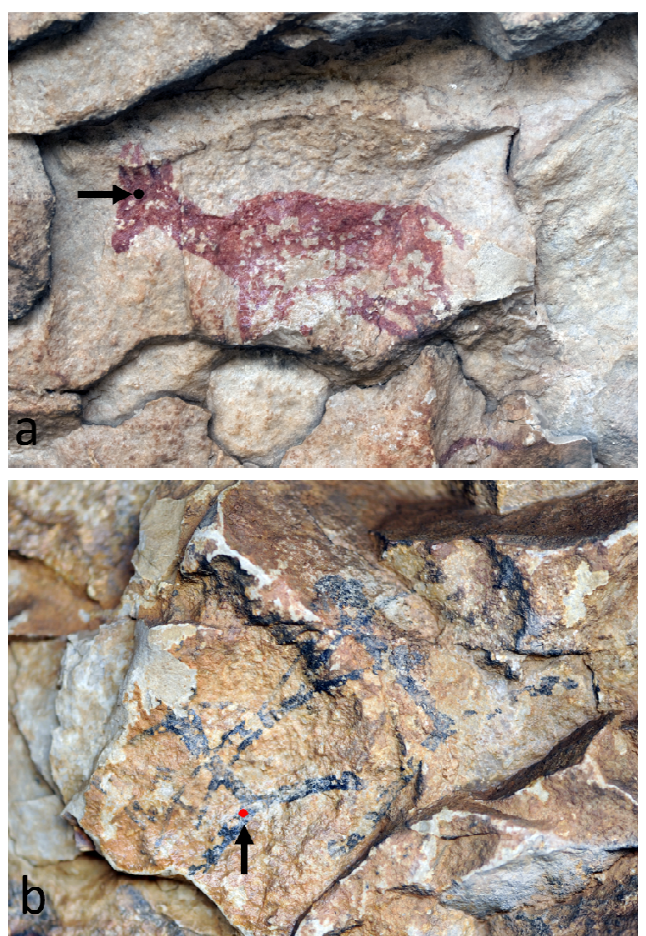

Figure 5. Examples of red (a) and black (b) painted zones evaluated in Cova Remígia shelters IV and V

The estimated intensity at the illuminated spot was 7.0 Mlx. Therefore, a 10-minute exposure to the light provided by the 
microfade tester is approximately equivalent to $1.2 \mathrm{Mlx} \times \mathrm{h}$. If one wants to correlate the exposure obtained using MFS to the one experienced by the paintings, a light monitoring campaign of at least one year needs to be conducted at the site. In this way, the total exposure received by the paintings can be calculated and any possible correlation with the exposure obtained using MFS can be studied. At this moment, the authors do not know what the actual exposure to sunlight is since there are many variables that need to be taken into account. For example, the typical illuminance of direct sunlight is approximately $100000 \mathrm{~lx}$, while that recorded on the shade remains usually below $10000 \mathrm{~lx}$. Therefore, it is important to determine the number of hours over an entire year when the paintings are exposed to direct and indirect sunlight.

A summary of MFS results is presented in Figure 6. The Delta $\mathrm{E}^{*}$ values provide a quantitative way of assessing the sensitivity of colored areas. An example of a red area evaluated (indicated by the red line) shows a similar fading curve to the one obtained for BW 3 confirming that this system has lower sensitivity to light irradiation relative to other less stable materials showing extremely high (BW 1) and very high sensitivity (BW 2). After 10 minutes, it can be observed that BW 1 experienced a color change with a final Delta $E^{*}$ of 5.5 units, while BW 2 and BW 3 are relatively more stable with final Delta $E^{*}$ values of 3.0 and 0.5 , respectively. Figure 5a shows one of these red zones, which was located in the head of an animal motif painted in shelter IV. The arrow indicates the approximate location of the irradiated spot shown as a black dot. The result obtained for the red zones is expected since red pigments most likely are Fe-based since it is known that these pigments prevail throughout the Levantine rock art zone (López-Montalvo et al., 2014). These systems containing Fe-based pigments generally exhibit good lightfastness properties. Druzik (2010) conducted a MFS study on rock art samples from China and his results on Fe-based pigments support this statement. In contrast, a black zone containing an organic pigment gave a similar response to the one observed for BW 2; with a final Delta $E^{*}$ of 2.7 (black discontinuous line). An example of one of the black areas tested is indicated by the arrow in Figure 5b. A red dot shows the approximate location of the evaluated spot on this depiction of a human figure. It is important to mention that this is only an estimation of the location of the spot since after the test it is not possible to visually identify color differences taking place in the tested area, even under a microscope. It should be pointed out that if a material registers a Delta $\mathrm{E}^{*} \geq 2$, then the color change is generally noticeable for most of the people. This means that the magnitude of this change is discernable by the naked eye. Mahy et al. (1994) reported a just noticeable difference as a Delta E* of 2.3 or higher for the CIELAB (1976) color space. Likewise, similar black areas containing organic pigments can be identified as systems with very high sensitivity to light. None of the evaluated zones showed a rate comparable to that of BW 1 , which is considered an extremely light sensitive material.

Although little or no changes were observed after comparing the initial and final reflectance curves registered for the red zones, it was possible to detect spectral changes for the black zone tested (Figure 7). The initial spectrum of the black zone shows a broad band in the $400-800 \mathrm{~nm}$ region with a maximum near $550 \mathrm{~nm}$ giving a greenish hue. A reduction on the intensity of the spectrum over the entire region is observed as a result of exposure to the light spot delivered by the microfade tester. This reduction in reflectance indicates that the color becomes darker. The discontinuous line shown in Figure 7 corresponds to the final spectrum obtained after conducting microfade testing of the black zone. The arrow indicates the direction of the spectral change. After comparing the initial and final spectrum, it can be observed that the Delta $E^{*}$ of approximately 3 units (see Figure 6) registered for the black painted zone is due to a reduction in the reflectance throughout the entire visible wavelength range.

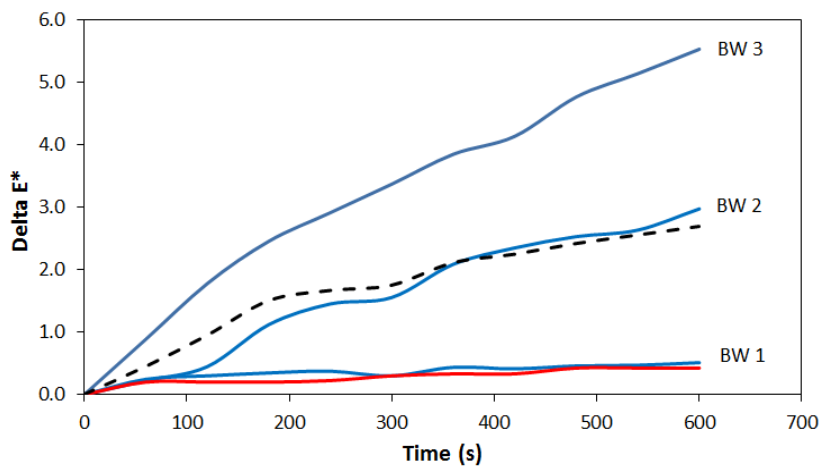

Figure 6. Microfading curves obtained for one spot painted in red and second one painted in black. The fading rates are compared to the ones registered for BW standards 1-3 under the same conditions.

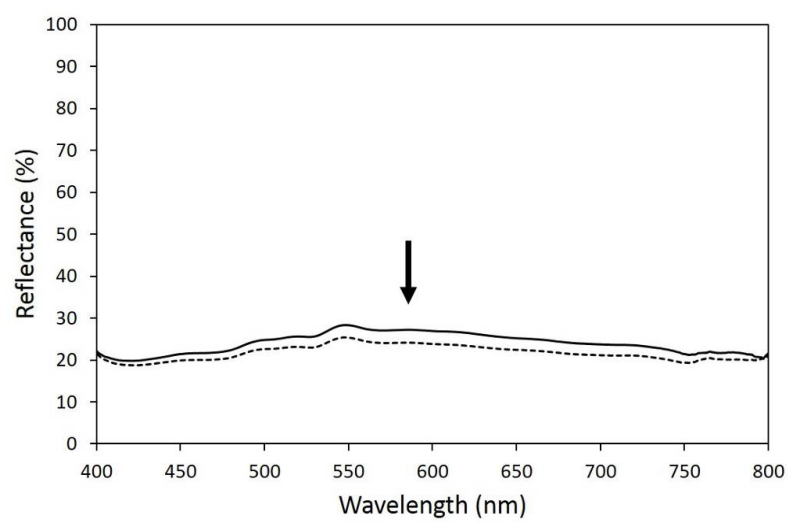

Figure 7. Reflectance curves of the black spot painted with organic pigment recorded at the beginning (solid line) and at the end (discontinuous line) of the microfading test.

\section{DISCUSSION}

It is important to highlight that MFS results generally only offer physical information about the photostability of a colorant in a colorant/binder/substrate system. In this sense, no characterization of the pigments was attempted since a spectral library of pigments has not been prepared yet. However, the results of a previous XRF spectrometry study conducted on a relevant site by Roldán et al. (2010) can be somehow correlated with the MFS results obtained at Cova Remígia. For example, Fe-based pigments are known for their high stability after long exposures to light and this property was confirmed by our MFS data. In contrast, the area painted with a black pigment of vegetable origin showed higher sensitivity to light than expected for this kind of pigment. It is known that even though black vegetable-derived pigments are extremely permanent, they may become greyer or less brown following prolonged exposure to light when in contact with water or if imperfectly carbonized. Although the origin of this unexpected change is unknown, a possible hypothesis is the contact of these materials with water, which is known for decreasing the light stability of this pigment. The lower stability of this pigment can also be due to 
chemical and physical interactions taking place at the pigment/substrate and pigment/calcite interlayers.

These data can provide an initial step towards the creation of a materials photosensitivity database, which can enhance the documentation of cultural heritage objects by adding a lightstability component. These results can be of value when describing the paintings and for explaining their long-term behaviour under current and future environmental conditions. Visual assessments were conducted after each test with the aim of detecting changes on the analysed spots. However, it was not possible to detect any change due to the use of high illumination directly on the paintings. It is important to emphasize that this equipment was designed to study museum objects, which are typically stored or exhibited under controlled environmental conditions. Since this was the first time that this technology is applied on the field, a light monitoring campaign that takes into account many variables (hours of direct/indirect sunlight, cloudy/sunny days, etc.) is needed prior to making any further correlations between the natural and the artificial exposures. In any case, the authors believe that archaeologists are now more eager to apply this technique when studying rock art sites.

It is important to emphasize that the color changes recorded with the MFS need to be analysed within their entire context. It is important to remember that this is a very small spot of light acting on the surface of a much larger object. The instrument has the capability of inducing color changes at a sub-millimetric scale with the aim of not leaving a visible mark behind. Color changes having Delta $E^{*}$ values of two or higher are typically detected if the two areas compared are fairly large (e.g. similar paints applied on two walls).

The deviations of accelerated aging from natural aging have been extensively investigated and the authors recognize that MFS is only a survey technique that can help to assess if there are any potential photosensitive materials in rock art systems. The results can be complementary to data obtained from other analytical techniques as well as to information available from climate monitoring stations. No predictions are possible due to the non-linearity between the changes experienced as part of a MFS test and variations observed due to natural aging processes.

The application of new scientific tools such as MFS in highly valuable prehistoric art was used with special care. Archaeologists as well as cultural heritage documentation specialists typically were concerned with the use of microfade testing on actual rock art paintings. However, our preliminary results can provide answers to some of the questions formulated by archaeologists and scientists currently involved in the study of rock art. Now it is confirmed that MFS is an adequate application tool to study the long-term behaviour to light of rock/pigment systems. It is evident that interdisciplinary collaboration is needed in order to conduct a comprehensive study of rock art paintings. Therefore, a multi-technique approach, which includes microfade testing data can really complement the documentation of cultural heritage objects by offering a new dimension in terms of aging processes and photostability of colored systems found in rock art.

\section{CONCLUSIONS}

This paper presents preliminary research results that confirm the value of interdisciplinary multifaceted analysis for better understanding of cultural heritage sites. The main results obtained in the present study can be summarized as follows:

1. MFS is a suitable technique for studying the response to light of rock/pigment systems found in rock art sites.

2. The optimal conditions for analysing the photostability of pigments in rock art paintings were identified. These include the use of light for accelerated aging with a similar spectral power distribution to that of natural daylight, modification of the instrumental setup to include UV radiation in the measurements, and finding areas of low specular reflection to minimize the error introduced by glossy surface effects that can interfere with the determination of the sensitivity of the pigment.

3. Systems containing Fe-based red pigments exhibited low sensitivity to the action of light showing a stability similar or higher than BW 3 .

4. Systems containing black pigments of vegetable origin were found to be very sensitive showing a changing rate similar to the one recorded for BW 2 . This result may due to the combined effect of high humidity and light irradiation as discussed above.

5. Technology approaches of both partners were compared and options for a comprehensive documentation of the paintings that includes spatial, spectral, and time components were outlined.

Future research contemplates further developing and using the microfade testing equipment on site. Once the access and the instrument's stability issues are solved and understood, one of the main areas of interest is to conduct a systematic study on a larger number of paintings found in several archaeological sites with the aim of comparing the results and creating a database of colorant stability. For this purpose, additional systematic studies are necessary using EDXRF and Raman spectroscopies with the aim of providing complementary information about the composition of the pigments.

\section{ACKNOWLEDGEMENTS}

This research was possible thanks to the financial support provided by COST Action TD1201, Colour and Space in Cultural Heritage $(\mathrm{COSCH})$. The authors also would like to thank the Generalitat Valenciana for providing access to the site during the measurement campaign. The analysis and graphic digital recording of Cova Remígia paintings are part of the projects PROMETEO/2008-165 and PROMETEO II/2013-016 of the Generalitat Valenciana Excellence Programme, as well as the "NEOSOCWESTMED" project $\left(n^{\circ} 628428\right)$ of the Marie Curie Actions of the $7^{\text {th }}$ Framework Research Programme of the European Commission. The authors acknowledge the research project HAR2014-59873-R from the Spanish Ministerio de Economía y Competitividad for providing financial funding that will help to increase the knowledge on this topic.

\section{REFERENCES}

Bacci, M., Cucci, C., Mencaglia, A.A., Mignani, A.G., Porcinai, S., 2004. Calibration and use of photosensitive materials for light monitoring in museums, blue wool standard 1 as a case study. Studies in Conservation, 49, pp. 85-98.

Brimblecombe, P., Grossi, C.M., Ian, H., 2011. Climate change critical to cultural heritage. In: Gökcekus, H., Türker, U., LaMoureaux, J.W. (eds) Survival and sustainability. 
Environmental Earth Sciences, Springer-Verlag, Berlin, pp. 195-205.

CIELAB 1976, 1978. Official recommendations on uniform color spaces, color difference equations, and metric color terms, Commission International de l'Éclairage, Vienna, Austria.

David, H., 2008. Contribución a la conservación del arte rupestre prehistórico. PhD Thesis, Polytechnic University of Valencia, Valencia, Spain.

del Hoyo-Meléndez, J.M., Mecklenburg, M.F., 2010. A survey on the light-fastness properties of organic-based Alaska Native artifacts. Journal of Cultural Heritage, 11, pp. 493-499.

Díez-Herrero, A., Gutiérrez-Pérez, I., Lario, J., Cañaveras, J.C., Benavente, D., Sánchez-Moral, S., Alonso-Azcárate, J., 2009. Analysis of potential direct insolation as a degradation factor of cave paintings in Villar del Humo, Cuenca, Central Spain. Geoarchaeology, 24, pp. 450-465.

Domingo I., Villaverde, V., López-Montalvo, E., Lerma, J.L., Cabrelles, M., 2013. Latest developments in rock art recording towards an integral documentation of Levantine rock art sites combining $2 \mathrm{D}$ and $3 \mathrm{D}$ recording techniques. Journal of Archaeological Science, 40, pp. 1879-1889.

Druzik, J., 2010. Evaluating the light sensitivity of paints in selected wall paintings at the Mogao Grottoes: Caves 217, 98 and 85. In: Agnew, N. (Ed), Conservation of Ancient Sites on the Silk Road, The Getty Conservation Institute, Los Angeles, pp. 457-463.

Ford, B., 2009. Non-destructive microfade testing at the National Museum of Australia. AICCM Bulletin, 32, pp. 54-64.

Giesen, M.J., Ung, A., Warke, P.A., Christgen, B., Mazel, A.D., Graham, D.W., 2014. Condition assessment and preservation of open-air rock art panels during environmental change. Journal of Cultural Heritage, 15(1), pp. 49-56.

López-Montalvo, E., Villaverde, V., Roldán, C., Murcia, S., Badal, E., 2014. An approximation to the study of black pigments in Cova Remigia (Castellón, Spain). Technical and cultural assessments of the use of carbon-based black pigments in Spanish Levantine Rock Art. Journal of Archaeological Science, 52, pp. 535-545.

Porcar,J.B., Obermaier,H., Breuil,H., 1935. Excavaciones en Cueva Remigia (Castellón). Memoria de la Junta Superior del Tesoro Artístico. Madrid, España.

Roldán, C., Murcia-Mascarós, S., Ferrero, J., Villaverde, V., López, E., Domingo, I., Martínez, R., Guillem, P.M., 2010. Application of field portable EDXRF spectrometry to analysis of pigments of Levantine rock art. X-ray spectrometry, 39(3), pp. 243-250.

Sarriá Boscovich, E., 1989. Las pinturas rupestres de Cova Remigia (Ares del Maeste, Castellón). Lucentum, VII-VIII, pp. 7-33.

Tse, S., Guild, S., Orlandini, V., Trojan-Bedynski, M., 2010. Microfade testing of $19^{\text {th }}$ century iron gall inks. In: Research and Technical Studies Specialty Group Postprints, American
Institute for Conservation, Milwaukee, United States, Vol. 2, pp. 56-73.

Whitmore, P.M., Pan, X., Bailie, C., 1999. Predicting the fading of objects: identification of fugitive colorants through direct nondestructive lightfastness measurements. Journal of the American Institute for Conservation, 38, pp. 395-409. 